\title{
Tannin-Mordant Coloration with Matcha (camelia sinensis) and Iron(II)-Lactate on Human Hair Tresses
}

\author{
Lusine Sargsyan ${ }^{1,2, *}$, Thomas Hippe ${ }^{1}$, Hartmut Manneck ${ }^{1}$ and Volkmar Vill ${ }^{2} \mathbb{D}$ \\ 1 R\&D Hair Color Level 3, Henkel AG \& Co KGaA, Hohenzollernring 125-127, 22763 Hamburg, Germany; \\ Thomas.Hippe@henkel.com (T.H.); Hartmut.Manneck@henkel.com (H.M.) \\ 2 Department of Chemistry, University of Hamburg, Martin-Luther-Kingplatz 6, 20146 Hamburg, Germany; \\ vill@chemie.uni-hamburg.de \\ * Correspondence: Lusine.Sargsyan@studium.uni-hamburg.de; Tel.: +49-8824-2410
}

Citation: Sargsyan, L.; Hippe, T.; Manneck, H.; Vill, V. Tannin-Mordant Coloration with Matcha (camelia sinensis) and Iron(II)-Lactate on Human Hair Tresses. Molecules 2021, 26, 829. https://doi.org/10.3390/ molecules 26040829

Academic Editors:

Teresa Escribano-Bailón and Ignacio García-Estévez

Received: 4 December 2020

Accepted: 2 February 2021

Published: 5 February 2021

Publisher's Note: MDPI stays neutral with regard to jurisdictional claims in published maps and institutional affiliations.

Copyright: (c) 2021 by the authors. Licensee MDPI, Basel, Switzerland. This article is an open access article distributed under the terms and conditions of the Creative Commons Attribution (CC BY) license (https:// creativecommons.org/licenses/by/ $4.0 /)$.

\begin{abstract}
The aim of this work was to optimize our natural hair dyeing system which we described in our previous work and to compare with other dyeing systems. Therefore, we investigated concentration limits of matcha and mordant and compared this new dyeing method with commercial permanent systems on the market. Completely unpigmented hair tresses were dyed with matcha powder (camelia sinensis) and iron(II)-lactate. To investigate the wash fastness and concentration limits, the differently dyed hair tresses were spectrophotometrically measured. The comparison of the damage potential for which cysteic acid is an indicator was measured by NIR. The concentration of matcha and mordant are responsible for the intensity of the color results. The higher the matcha or the mordant concentration, the darker the color results of the dyed hair tresses. Hair damage of matcha mordant dyeing is comparable with results of commercial permanent hair coloration systems. Moreover, the results of wash fastness of matcha mordant dyed hair tresses is comparable and even better by tendency to permanent colored hair tresses.
\end{abstract}

Keywords: tannin-mordant-complex; natural hair coloration; matcha; $\Delta$ E-values; wash fastness

\section{Introduction}

One of the most desirable goals in the hair dye industry is to develop a color that will permanently dye the hair without damaging, while still providing long-lasting color intensity. The interest in natural and renewable raw materials as an alternative source has increased in many areas. [1] Natural hair dyeing colorants such as henna are widely used in natural cosmetics. The main coloring agent in henna leaves is lawsone (2-hydroxy1,4-naphthoquinone), also known as CI Natural Orange 6, which is responsible for the coloration of the hair fibers and leads to red-orange color results. [2,3].

Natural colorants such as iron-gall inks have been used for thousands of years. They represent a colored tannin-iron complex. They have been used to dye leather, fabrics, and other materials, whereby different plants provide different tanning agents, thus creating a wide variety of colors [4].

There are many categories of synthetic hair dyes, which are differentiated by their ability to penetrate the surface or deeper parts of the hair shaft and the longevity of the color after washing. The two most used types of hair dyes are temporary and permanent colorations. Temporary dyes damage the hair less than permanent dyes and are not capable to reach the cortex. [3] The lastingness of this intensive colors is limited to 5-8 hair washes.

An alternative method instead of henna and synthetic coloration could be a dyeing system with polyphenolic compounds of natural origin and mordants with other color results than reddish ones.

While the polyphenolic compound itself has only a low substantivity to the hair fiber, it is necessary to use metal salts as mordants to increase the affinity by formation 
of stable colored complexes. [5] Iron salts, especially iron(II)-lactate, form intensive coloration in combination with polyphenolic compounds in comparison to other metal salts as investigated in our previous work [6].

Tannic substances can be extracted from different parts of plants as barks and leaves and also from tea to use it for hair dyeing methods. [5] All investigations in this work were done with matcha tea powder (camelia sinensis) itself because of the tannic and catechine compounds which are present in the powder.

In our previous work, we could achieve intensive coloration on pre-bleached hair tresses. [6] In this current work, the investigations were carried out on unpigmented hair tresses to determine whether intensive color results can also be achieved on untreated hair tresses. In addition, the wash fastness and the damage potential were compared to commercially available permanent dyeing systems. The examination of hair tresses using near-Infrared (NIR)-spectroscopy has become an established method regarding the detection of cysteic acid. For instance, Pande and Yang examined hair tresses damaged by oxidative treatment using NIR spectroscopy. [7]. Miyamae et al. applied partial least squares (PLS) regression to NIR-DR spectra of human hair after mean centering (MC), standard normal variate (SNV), and first derivative (1d) or second derivative ( $2 \mathrm{~d}$ ) analysis to develop calibration models that predict physical properties of human hair [8]. Thus, the cysteic acid determination in our studies was also carried out by NIR spectroscopy and determined by creating a calibration set and a validation set.

\section{Results and Discussion}

\subsection{Investigation of the Concentration of Matcha}

To investigate the dependence of the concentration of the tanning agent, herein matcha, and the color intensity, the color change values were determined and presented as box plots in Figure 1. The abscissa represents the concentration of matcha and the ordinate represents the color change as $\Delta \mathrm{E}$-value after each treatment. The $\Delta \mathrm{E}$-value describes absolute color differences calculated by the Euclidean color distance formula as described in Section 4.5 in Formula (1). Moreover, the color coordinates $\mathrm{L}, \mathrm{a}, \mathrm{b}$, and $\Delta \mathrm{E}$ are listed in Table 1.

Compared to the reference, which is the untreated hair tress, all $\Delta \mathrm{E}$-values of the hair tresses treated with 1-30 wt\% matcha and then treated with mordant differ statistically significantly with $(p \leq 0.001)$.

No more significant differences $(p=1)$ are identifiable between the $\Delta \mathrm{E}$-values of hair tresses dyed with $20 \mathrm{wt} \%$ and $30 \mathrm{wt} \%$ matcha and then with $1 \mathrm{wt} \%$ iron(II)-lactate.

Despite significant differences with $(p \leq 0.001)$ between hair tresses, which where dyed with $10 \mathrm{wt} \%$ and $20 \mathrm{wt} \%$ matcha and afterwards with $1 \mathrm{wt} \%$ iron(II)-lactate, the $\Delta \mathrm{E}$-values only raise low.

Higher concentration of matcha tends to result in more intense colors. From these investigations, it is evident that the color intensity correlates with the concentration of matcha. An optimal color result can be expected at a concentration of $10 \mathrm{wt} \%$ matcha or more. 


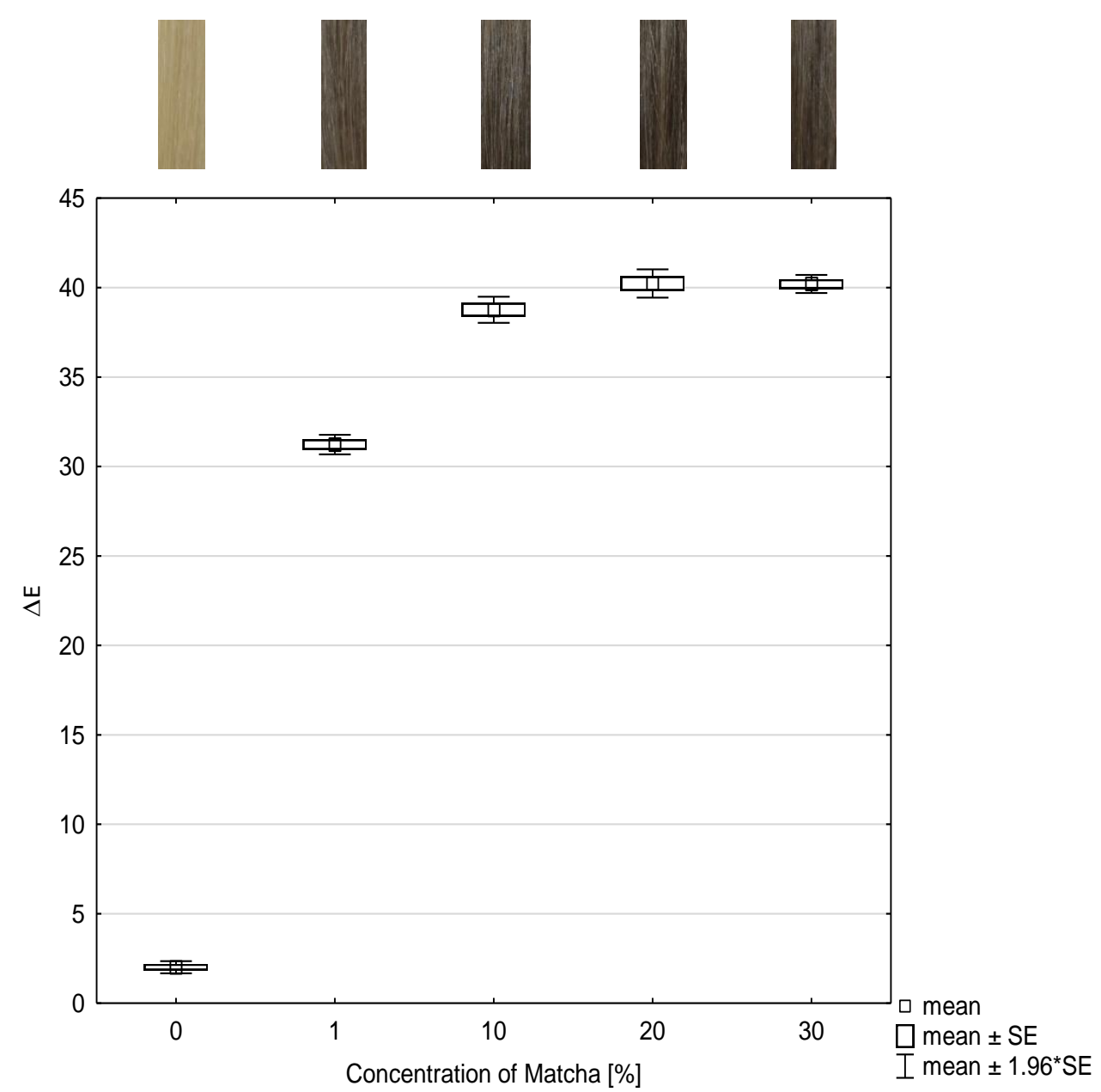

Figure 1. Box and whisker plot of color change $\Delta \mathrm{E}$-value of dyed hair tresses with different concentrations of matcha in combination with $1 \mathrm{wt} \%$ iron(II)-lactate and the corresponding photographs of the hair tresses $(\mathrm{n}=10)$. SE: standard error.

Table 1. Color coordinates, $\mathrm{L}, \mathrm{a}, \mathrm{b}$, and $\Delta \mathrm{E}$ of hair tresses dyed with different concentrations of matcha in combination with $1 \mathrm{wt} \%$ iron(II)-lactate $(\mathrm{n}=10)$. SD: standard deviation.

\begin{tabular}{cccccc}
\hline \multicolumn{6}{c}{ Concentration of Matcha } \\
\hline $\begin{array}{c}\text { Color } \\
\text { Coordinates }\end{array}$ & 0 SD & 1 SD & 10 SD & 20 SD & 30 SD \\
\hline $\mathrm{L}$ & $76.98 \pm 0.41$ & $49.33 \pm 0.87$ & $42.22 \pm 1.15$ & $40.81 \pm 1.24$ & $41.15 \pm 0.72$ \\
$\mathrm{a}$ & $0.42 \pm 0.12$ & $0.81 \pm 0.1$ & $1.1 \pm 0.12$ & $1.18 \pm 0.11$ & $1.07 \pm 0.08$ \\
$\mathrm{~b}$ & $19.51 \pm 0.54$ & $2.75 \pm 0,47$ & $0.1 \pm 0.42$ & $-0.37 \pm 0.46$ & $-0.98 \pm 0.42$ \\
$\Delta \mathrm{E}$ & $2.01 \pm 0.55$ & $31.23 \pm 0.88$ & $38.76 \pm 1.18$ & $40.23 \pm 1.27$ & $40.2 \pm 0.82$ \\
\hline
\end{tabular}

\subsection{Investigation of the Concentration of Iron(II)-Lactate}

To investigate the dependence of the concentration of the mordant, herein iron(II)lactate, and the color intensity, the color change values were determined and presented as box plots in Figure 2. The abscissa represents the concentration of iron(II)-lactate and the ordinate represents the color change as $\Delta \mathrm{E}$-value after each treatment. Moreover, the color coordinates $\mathrm{L}, \mathrm{a}, \mathrm{b}$, and $\Delta \mathrm{E}$ are listed in Table 2 . 


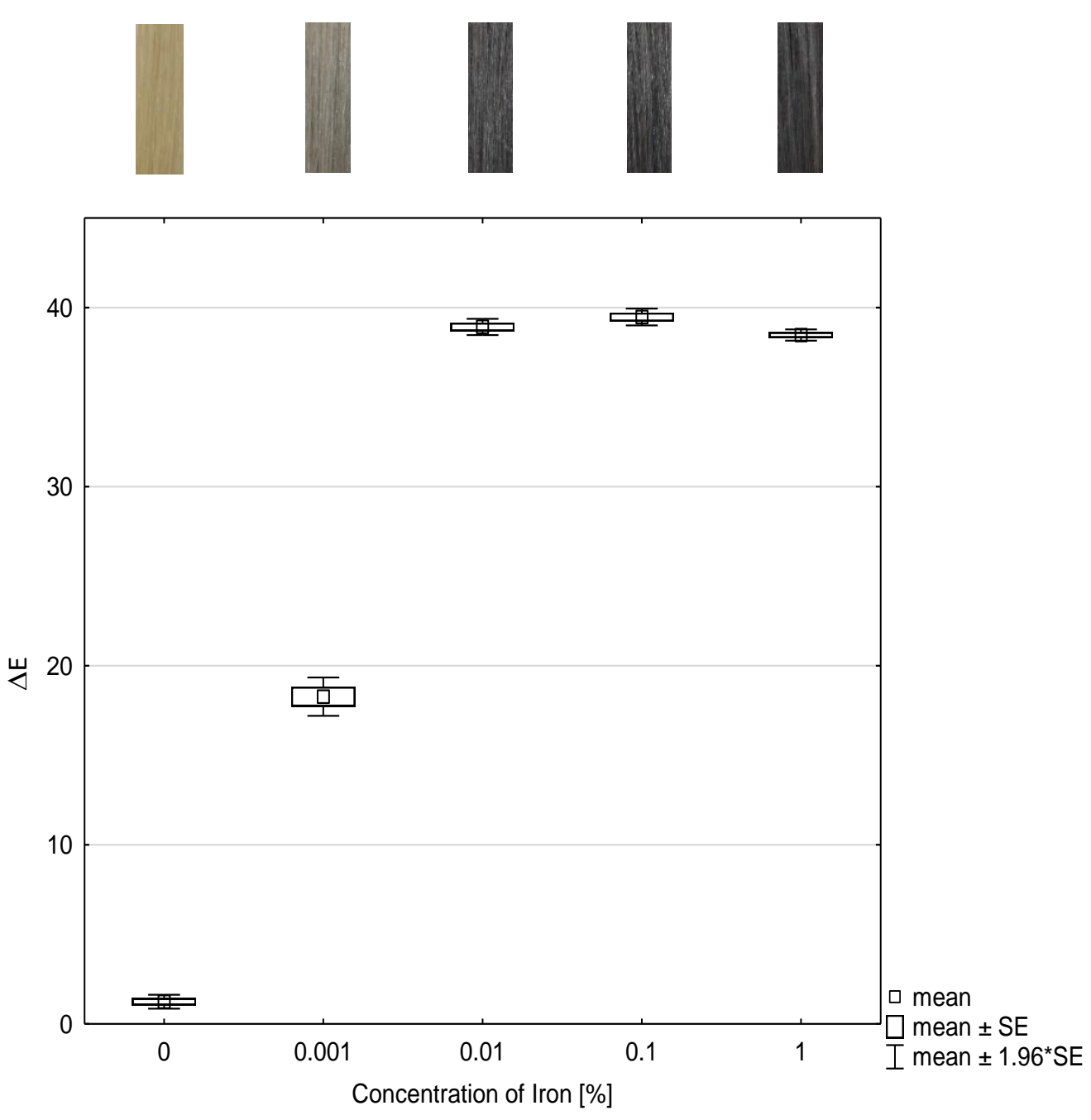

Figure 2. Box and whisker plot of color change $\Delta \mathrm{E}$-value of dyed hair tresses with different concentrations of iron(II)-lactate in combination with $10 \mathrm{wt} \%$ matcha and the corresponding photographs of the hair tresses $(\mathrm{n}=10)$. SE: standard error.

Table 2. Color coordinates, $\mathrm{L}, \mathrm{a}, \mathrm{b}$, and $\Delta \mathrm{E}$ of hair tresses dyed with different concentrations of iron(II)-lactate in combination with $10 \mathrm{wt} \%$ matcha $(\mathrm{n}=10)$. SD: standard deviation.

\begin{tabular}{cccccc}
\hline \multicolumn{5}{c}{ Concentration of Iron(II)-Lactate } \\
\hline $\begin{array}{c}\text { Color } \\
\text { Coordinates }\end{array}$ & 0 SD & $\mathbf{0 . 0 0 1 ~ S D ~}$ & $\mathbf{0 . 0 1 0 ~ S D ~}$ & $\mathbf{0 . 1}$ SD & 1 SD \\
\hline $\mathrm{L}$ & $76.60 \pm 0.74$ & $62.67 \pm 1.41$ & $43.56 \pm 0.74$ & $43.1 \pm 0.81$ & $70.17 \pm 0.86$ \\
$\mathrm{a}$ & $0.41 \pm 0.23$ & $0.57 \pm 0.14$ & $1.1 \pm 0.06$ & $0.94 \pm 0.1$ & $2.05 \pm 0.3$ \\
$\mathrm{~b}$ & $18.08 \pm 0.71$ & $7.51 \pm 1.05$ & $-0.84 \pm 0.3$ & $-1.16 \pm 0.42$ & $18.09 \pm 0.75$ \\
$\Delta \mathrm{E}$ & $1.24 \pm 0.62$ & $18.28 \pm 1.72$ & $38.92 \pm 0.73$ & $39.47 \pm 0.76$ & $7.55 \pm 0.88$ \\
\hline
\end{tabular}

As in the study of the concentration of the tanning agent, Figure 2 also shows that all $\Delta \mathrm{E}$-values of the treated hair tresses differ statistically significantly with $(p \leq 0.001)$ from the $\Delta \mathrm{E}$-value of the untreated hair tress, which is the reference.

The delta $\Delta \mathrm{E}$-values of hair tresses treated with $0.01 \mathrm{wt} \%$ iron(II)-lactate and matcha do not show statistically significant differences $(p=1)$ compared to the $\Delta \mathrm{E}$-values treated with $0.1 \mathrm{wt} \%$ or $1 \mathrm{wt} \%$ iron(II)-lactate.

Intensive color results can be achieved at concentrations as low as $0.01 \mathrm{wt} \%$ iron(II)lactate. From these investigations, it is evident that the color intensity correlates with the concentration of iron(II)-lactate as mordant. An optimal color result can be expected at a concentration of $0.01 \mathrm{wt} \%$ of iron(II)-lactate or more. 


\subsection{NIR-Measurement of Cysteic Acid Amount of Matcha and Mordant and Dove Grey Dyed} Hair Tresses

To obtain information on the damage potential of the tanning and mordant dyeing, the cysteic acid amount was determined using NIR measurements. The relevant NIRrange for the analysis were the range of the wavelength 7300 to $4020 \mathrm{~cm}^{-1}$ as shown in Figures 3 and 4 . The abscissa represents each treatment and the ordinate represents the amount of cysteic acid after each treatment as shown in Figure 5.

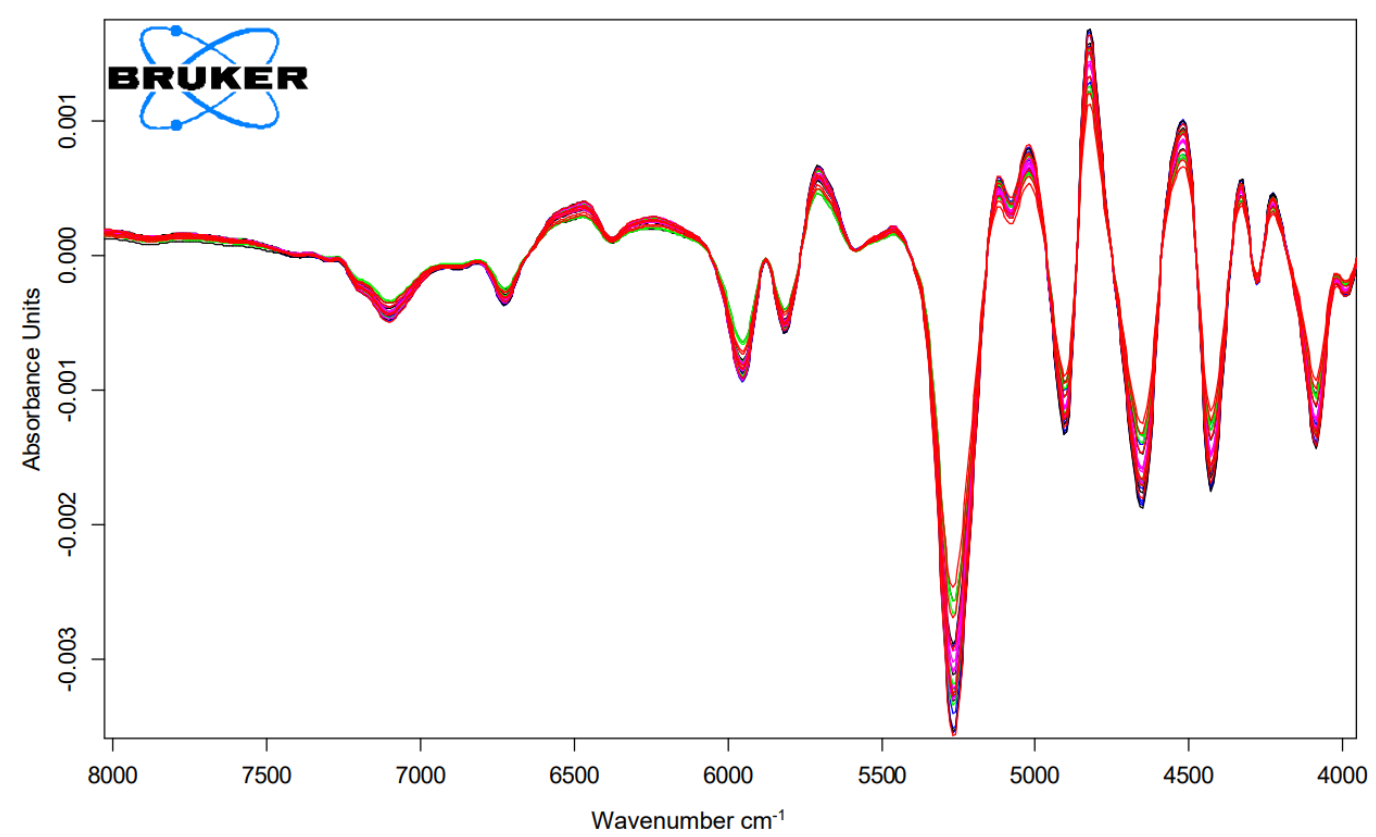

Figure 3. First derivation of FT-NIR-spectra of hair tresses after 3 times bleaching and dyed with matcha and iron-(II)-lactate with $n=5$.

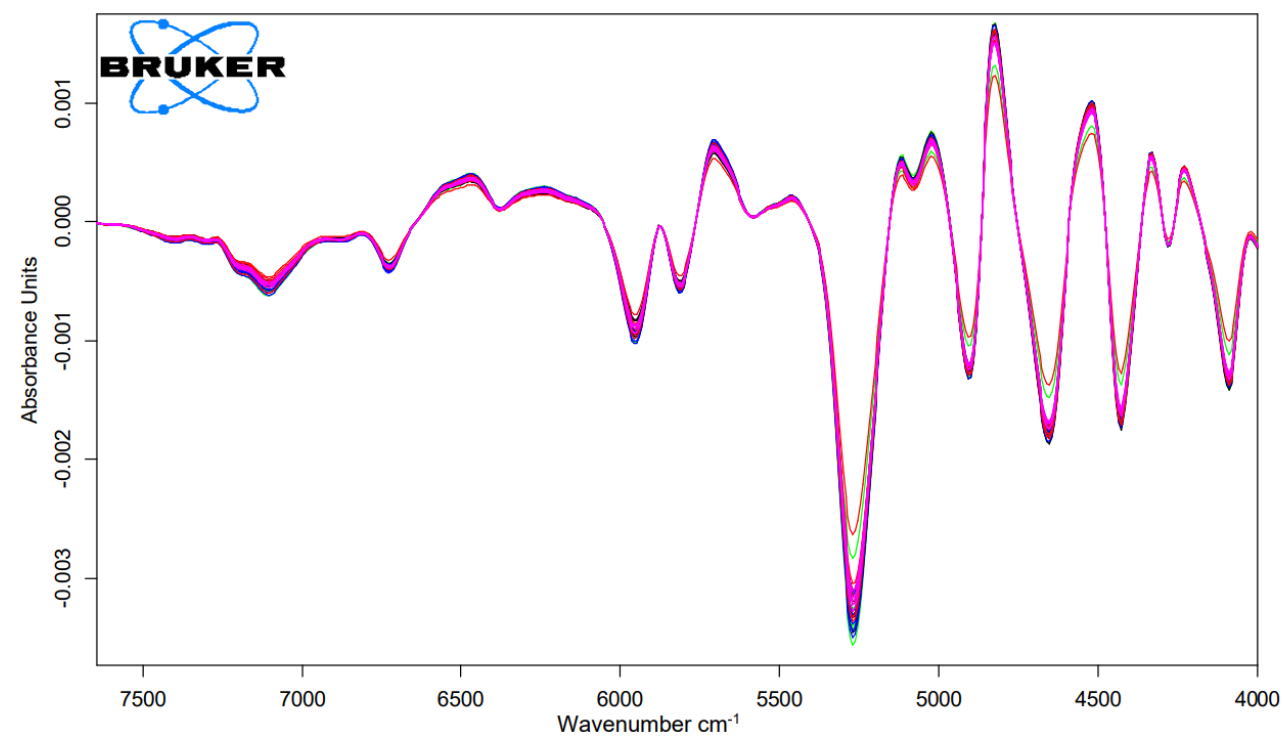

Figure 4. First derivation FT-NIR-spectra of hair tresses after 3 times bleaching and dyed with Dove Grey with $n=5$. 


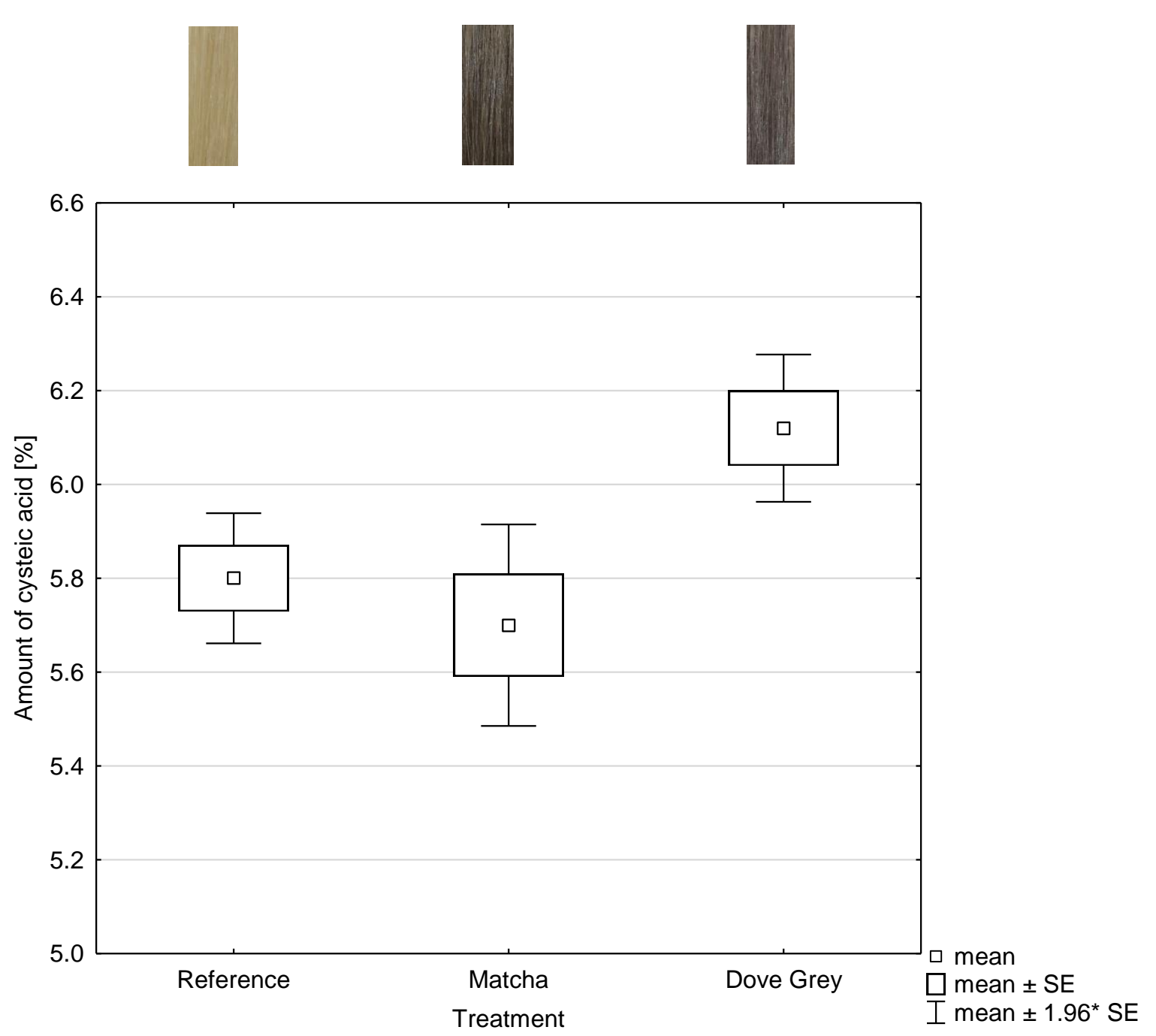

Figure 5. Box and whisker plot of comparison to untreated hair tresses as reference of the amount of cysteic acid amount of hair tresses treated with $10 \mathrm{wt} \%$ matcha in combination with $1 \mathrm{wt} \%$ iron(II)-lactate and hair tresses dyed with Dove Grey with the corresponding photographs of the hair tresses $(n=5)$. SE: standard error.

The product of oxidative treatments is cysteic acid, which is an indicator of damage to the hair structure. The higher the cysteic acid content, the more serious the damage [9]. No statistical differences $(p=1)$ can be observed between the 3 times bleached hair tress, which is the reference, and both dyed hair tresses. A higher number of samples or a confidence level of $10 \mathrm{wt} \%$ would probably lead to significant differences between the cysteic acid amount of the reference and the cysteic acid amount of Dove Grey (Igora Royal Absolutes Silverwhite, Schwarzkopf) treated hair tresses. Statistical differences with $(p \leq 0.001)$ between the cysteic acid amount of matcha and iron(II)-lactate dyed and Dove Grey treated hair tresses are visible. The cysteic acid amount of Dove Grey dyed hair tresses is higher by tendency as shown in Figure 5.

The potential to damage the hair is low or almost non-existent in both treatments. Thus, the hair coloration by using tanning agents and mordants is comparable and even better by tendency to a permanent hair coloration system.

\subsection{Wash Fastness of Matcha and Mordant and Dove Grey Dyed Hair Tresses}

To test the wash fastness, matcha and iron(II)-lactate treated hair tresses and Dove Grey dyed hair tresses were hand washed up to 30 times and measured spectrophotometrically. The abscissa represents each number of hair washing (HW) and the product which was used for the treatment. The ordinate represents the $\Delta \mathrm{E}$-values after of each treatment after 
the number of hair washings as shown in Figure 6. Moreover, the color coordinates L, a, b, and $\Delta \mathrm{E}$ are listed in Tables 3 and 4.
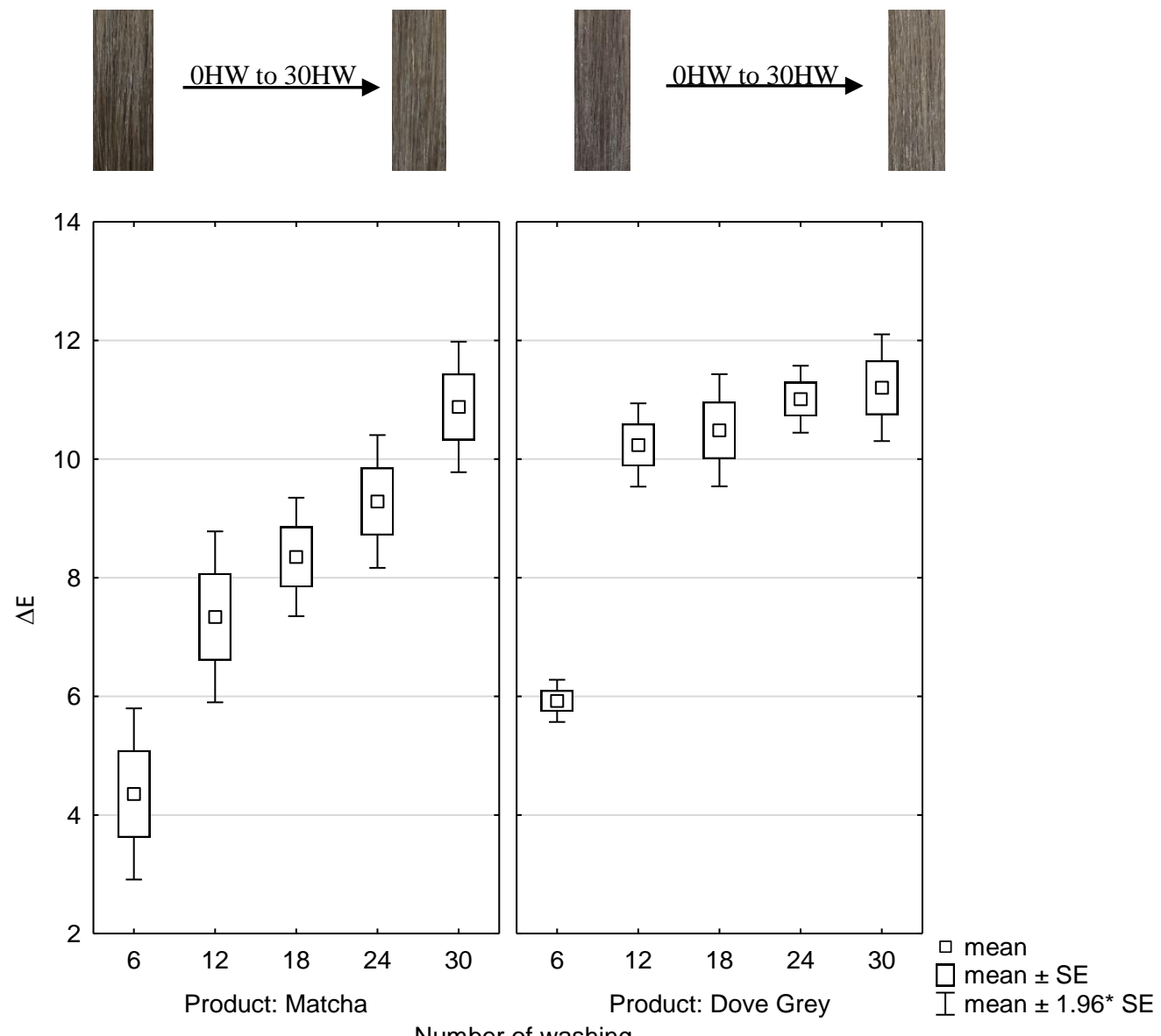

Figure 6. Box and whisker plots of color change $\Delta \mathrm{E}$ - values after washing numbers of 6 to 30 of dyed hair tresses with $10 \mathrm{wt} \%$ matcha in combination with $1 \mathrm{wt} \%$ iron(II)-lactate compared to hairs tresses dyed with Dove Grey and the corresponding photographs of the hair tresses from the reference 0 hair washes to 30 hair washes $(n=5)$. SE: standard error.

Table 3. Color coordinates, $\mathrm{L}, \mathrm{a}, \mathrm{b}$, and $\Delta \mathrm{E}$ of hair tresses dyed with commercial hair color Igora Royal Silverwhite Dove Grey $(\mathrm{n}=5)$. SD: standard deviation.

\begin{tabular}{cccccc}
\hline \multicolumn{6}{c}{ Number of Hair Washes of Dove Grey } \\
\hline $\begin{array}{c}\text { Color } \\
\text { Coordinates }\end{array}$ & 6 SD & 12 SD & 18 SD & 24 SD & 30 SD \\
\hline $\mathrm{L}$ & $45.59 \pm 0.37$ & $49.47 \pm 0.93$ & $49.6 \pm 1.2$ & $50.01 \pm 0.76$ & $50.28 \pm 1.12$ \\
$\mathrm{a}$ & $1.4 \pm 0.08$ & $1.7 \pm 0.1$ & $1.69 \pm 0.15$ & $1.72 \pm 0.09$ & $1.84 \pm 0.05$ \\
$\mathrm{~b}$ & $5.7 \pm 0.24$ & $7.59 \pm 0.19$ & $7.89 \pm 0.22$ & $8.26 \pm 0.31$ & $8.31 \pm 0.29$ \\
$\Delta \mathrm{E}$ & $5.92 \pm 0.4$ & $10.24 \pm 0.8$ & $10.49 \pm 1.08$ & $11.01 \pm 0.64$ & $11.2 \pm 1.03$ \\
\hline
\end{tabular}


Table 4. Color coordinates, $\mathrm{L}, \mathrm{a}, \mathrm{b}$, and $\Delta \mathrm{E}$ of hair tresses dyed with iron(II)-lactate in combination with $10 \mathrm{wt} \%$ matcha $(\mathrm{n}=5)$. SD: standard deviation.

\begin{tabular}{cccccc}
\hline \multicolumn{6}{c}{ Number of Hair Washes of Matcha and Iron(II)-lactate } \\
\hline $\begin{array}{c}\text { Color } \\
\text { Coordinates }\end{array}$ & 6 SD & 12 SD & 18 SD & 24 SD & 30 SD \\
\hline L & $44.09 \pm 2.12$ & $48.03 \pm 1.82$ & $48.83 \pm 1.3$ & $49.36 \pm 1.51$ & $51.03 \pm 1.31$ \\
a & $0.93 \pm 0.07$ & $1.48 \pm 0.13$ & $1.51 \pm 0.12$ & $1.71 \pm 0.78$ & $1.53 \pm 0.06$ \\
b & $3.53 \pm 0.76$ & $7.05 \pm 0.41$ & $7.7 \pm 0.37$ & $8.54 \pm 0.22$ & $8.98 \pm 0.36$ \\
$\Delta \mathrm{E}$ & $4.35 \pm 1.65$ & $7.34 \pm 1.64$ & $8.35 \pm 1.14$ & $9.92 \pm 1.28$ & $10.88 \pm 1.25$ \\
\hline
\end{tabular}

It can be observed that the removal of hair color is even when the hair tresses are dyed with matcha and iron(II)-lactate. When coloring with matcha and iron(II)-lactate, the $\Delta \mathrm{E}$-values of the hair tresses, which were washed up to 6 times, differ statistically significant with $(p \leq 0.001)$ from all other hair washes up to 30 times.

Significant differences with $(p \leq 0.001)$ can be noticed between the $\Delta \mathrm{E}$-values of the hair tresses which were washed up to 12 times and the hair tresses washed up to 30 times after dyed with matcha and iron(II)-lactate. Therefore, the color will not change statistically significant after more than 12 hair washes, when hair tresses are dyed with matcha and iron(II)-lactate.

When coloring with Dove Grey, the $\Delta \mathrm{E}$-values of the hair tresses, only which were washed up to 6 times, differ statistically significant with $(p \leq 0.001)$ from all other hair washes up to 30 times. Therefore, the color will not change statistically significant after more than 6 hair washes, when hair tresses are dyed with Dove Grey.

The $\Delta \mathrm{E}$-values of matcha and iron(II)-lactate dyed hair tresses and Dove Grey dyed hair tresses are comparable after 30 hair washes.

This means that the new dyeing system with matcha and iron(II)-lactate can also keep up with the tests of wash fastness with a permanent hair dye as Dove Grey.

\subsection{Possible Chemical Bonds on the Hair Fibre after Tannin and Mordant Dyeing}

According to the investigations of Covington A. D., the protein tannin interactions are based on various types of bonds as hydrogen bonds, salt links between amino side chains and carboxylic acid groups, or hydrophobic interactions [10].

The following Figure 7 shows possible bonds and interactions of the hair fiber with ingredients of matcha, here a flavonoid, and iron. The mesomeric effect and the complex bonds that can be formed from the iron ion to the hydroxy groups of the flavonols are shown. It can be seen that the iron can be in a boundary state as an anion covalently bound with the charge -3 or coordinately bound with the charge +3 . Furthermore, Figure 7 shows the ionic bond between a negative charged oxygen of the flavonol and a positive charged amino side chain group. Numerous hydrogen bonds can also be formed between the hydroxy groups of flavonol and keratinous hair structure. 


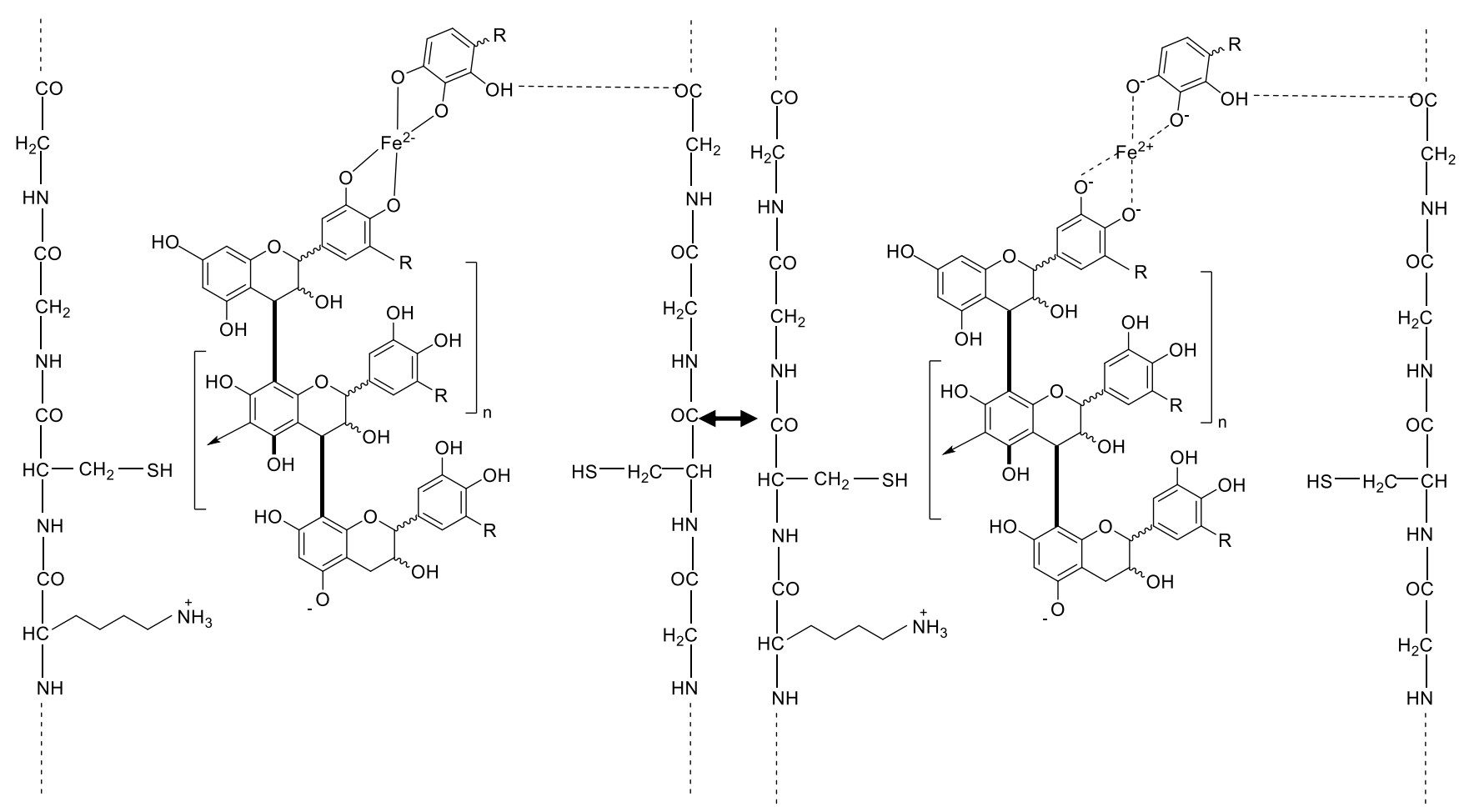

Figure 7. Possible interactions between hair fibers and flavonol compounds of matcha and the mesomeric effect of iron(II)-lactate where $\mathrm{R}=-\mathrm{H},-\mathrm{CH}$, or $-\mathrm{OH}$.

\section{Conclusions}

These studies show the potential of the hair dye system developed here to compete in the hair dye industry. The investigations of the damage potential and the wash fastness with a permanent coloring product on the market show that this system provides comparable and better results. To confirm our obtained results, further investigations are necessary. For example, other parameters can also be investigated before in vivo experiments can be performed. In addition, the exposure times can still be optimized, and the sequence of the procedure can be varied. Further investigations with different tanning agents and mordants should be carried out to generate additional color shades.

\section{Materials and Methods}

Hair tresses were obtained from the leading manufacturer Kerling International Haarfabrik $\mathrm{GmbH}$ (Backnang, Germany) with a total length of $10 \mathrm{~cm}$ of which $8 \mathrm{~cm}$ include hair fibers. Completely unpigmented hair tresses from Caucasians with $0.45 \pm 0.05 \mathrm{~g}$ weight, excluding glue bond, are used for the investigations in this work.

\subsection{Application of Permanent Coloration}

To compare vegetable tannin coloration with commercially available permanent hair color for professional hairdressing needs, Igora Royal Absolutes Silverwhite with the color direction Dove Grey (Schwarzkopf Professional, Düsseldorf, Germany) was used. Ratio of color cream to developer is 1:1 with an application time of $20 \mathrm{~min}$ and 3\% developer. After mixing of developer and color cream $9 \mathrm{~g}$ for one hair tress was used.

\subsection{Method of Matcha and Mordant Dyeing}

All investigations according to mordant coloration where done with matcha tea powder and iron(II)-lactate. The matcha tea used in this work was obtained from The Tea Company GmbH \& Co. KG (Neu Wulmstorf, Germany) with 100\% origin in Japan and the Article No. 174077. Tencha (camellia sinensis) is the origin product of which the matcha 
powder is manufactured by stonegrounds. [11] As shown in Figure 8, the flowchart of the complete tannin-mordant dyeing method is listed and will be described more precise in the following. Matcha solutions of $1 \mathrm{wt} \%, 10 \mathrm{wt} \%, 20 \mathrm{wt} \%$, and $30 \mathrm{wt} \%$, whereby $1 \mathrm{wt} \%$ matcha solution contains about $0.3 \mathrm{wt} \%$ polyphenols, were prepared in a buffer system of $\mathrm{pH}=5$. (Gentle to the hair, as the ISP of the hair is about $\mathrm{pH} 4.6$ ). The hair tresses were each treated for $30 \mathrm{~min}$ in the respective solution $(100 \mathrm{~mL} / \mathrm{g})$ and then rinsed under running deionized water for 1 min under 20 times combing. Afterwards, the hair braids were dried with a commercially available hair dryer at a defined distance and temperature ( $\mathrm{T}=80 \pm 5^{\circ} \mathrm{C} ; \mathrm{d}=10 \mathrm{~cm}$ ) under 20 -fold combing.

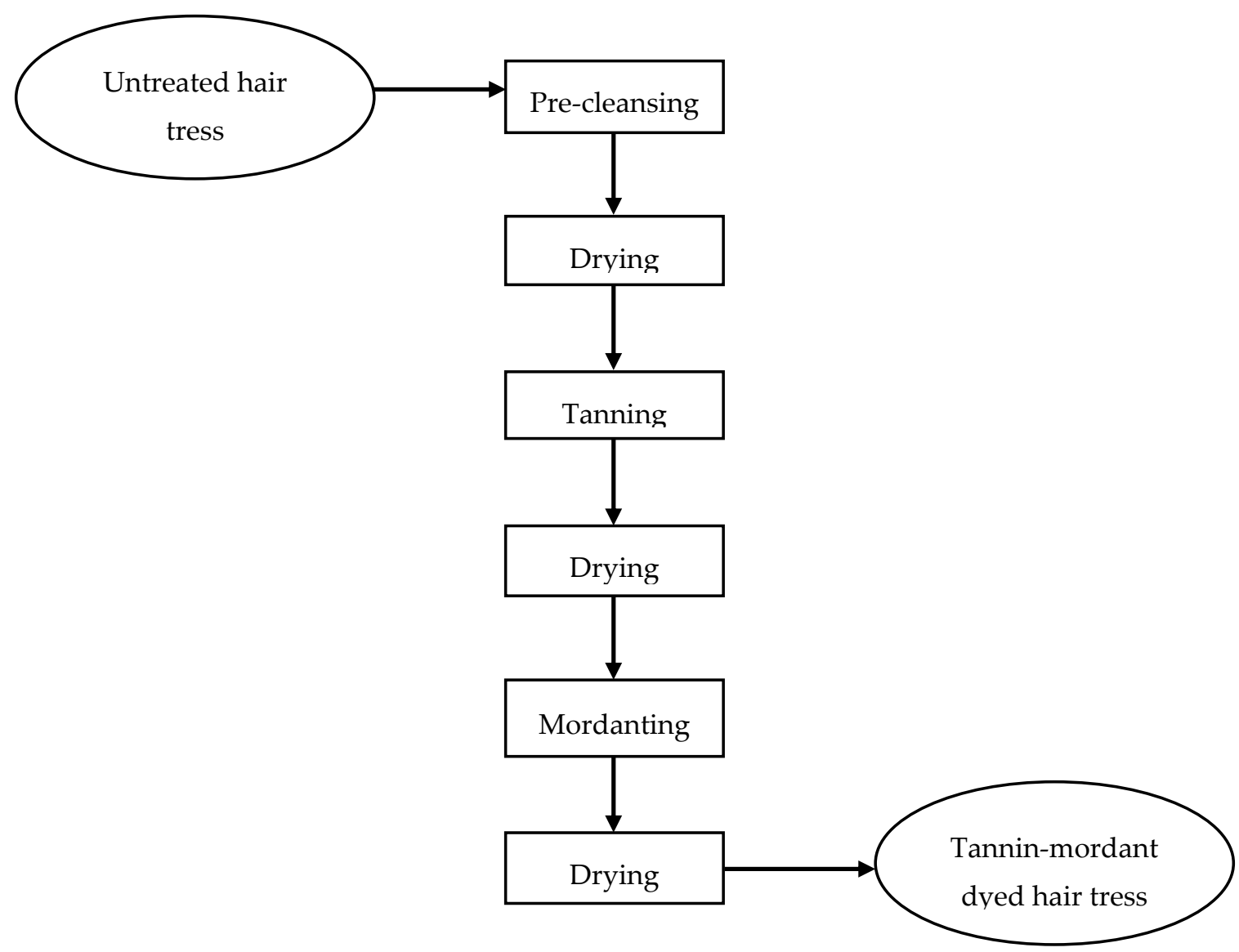

Figure 8. Flowchart of complete dyeing method.

Subsequently, $0.001-1 \mathrm{wt} \%$ metal salt solutions were prepared. The tannin-treated hair tresses were each treated for $30 \mathrm{~min}$ in the respective solution $(100 \mathrm{~mL} / \mathrm{g})$ and then rinsed under running deionized water for 1 min under 20-fold combing. Afterwards, the hair tresses were dried with a commercially available hair dryer at a defined distance and temperature $\left(\mathrm{T}=80 \pm 5{ }^{\circ} \mathrm{C} ; \mathrm{d}=10 \mathrm{~cm}\right)$ under 20-fold combing.

\subsection{Method of Wash Fastness}

The hair strands were washed under deionized running water with a volume flow of $\mathrm{V}=40 \pm 20 \mathrm{~mL} / \mathrm{s}\left(\mathrm{T}=33 \pm 2{ }^{\circ} \mathrm{C}\right)$ for $1 \mathrm{~min}$ to remove coarse contaminants first. To review the wash fastness of the color, the wet hair tresses were washed up to 30 times by hand using $0.5 \pm 0.02 \mathrm{~g} /$ hair commercially available shampoo (Schauma 7 Kräuter, Schwarzkopf). The 7 Herbs Shampoo was massaged in 10 times with a 5-fold circular motion with the thumb and forefinger and constant pressure from the adhesive bond to the tip of the hair. After incorporation of the shampoo, the hair tresses were rinsed out under running deionized water under deionized running water with a volume flow of $\mathrm{V}=40 \pm 20 \mathrm{~mL} / \mathrm{s}\left(\mathrm{T}=33 \pm 2{ }^{\circ} \mathrm{C}\right)$ for $1 \mathrm{~min}$. After rinsing, the hair tresses were detangled 
by combing them 20 times, starting from the adhesive bond up to the tip of the hair. After cleaning and combing, the hair tresses were dried with a commercially available hair dryer at a defined distance and temperature $\left(T=80 \pm 5^{\circ} \mathrm{C} ; \mathrm{d}=10 \mathrm{~cm}\right)$. This process was repeated up to 30 hair washes.

\subsection{Cysteic Acid Measurement with NIR-Spectroscopy}

Additionally, the samples were measured near infrared (NIR) spectroscopically with the integrating sphere module at 6 different sample positions in diffuse reflection. The spectra were recorded with a MPA ${ }^{\mathrm{TM}}$ FT-NIR spectrometer from Bruker Optik GmbH. The NIR-range covers the wavenumber range from 12,500 to $4000 \mathrm{~cm}^{-1}$ and is characteristic for overtone and combination oscillations of e.g., $\mathrm{CH}-, \mathrm{OH}_{-}$, and $\mathrm{NH}$ - groups. The measurements of the samples were performed in transmission at a resolution of $16 \mathrm{~cm}^{-1}$ and a scan number of 64 . The relevant NIR-range for the analysis were the range 7300 to $4020 \mathrm{~cm}^{-1}$. A partial least squares (PLS) regression of spectroscopic data and corresponding concentration values of the individual components was used to create a calibration model. The basis of the calibration work was a set of reference samples with defined concentrations.

The PLS-model is improved by changing the frequency range, mathematical data pre-treatment (first derivation), selecting the appropriate number of factors and automatic outlier detection. Here, the factor number is equal to the number of PLS-factors. The concentration and spectral data matrix were decomposed into scores and loading vectors by the PLS algorithm. The model created in each case was validated by the chemometric method.

\subsection{Spectrophotometric Measurement with Data Color}

The matcha and iron(II)-lactate hair tresses were measured spectrophotometrically using a Datacolor SF600 Spectraflash device. A D65 illuminant and diffuse $/ 8^{\circ}$ optical configuration were used for the spectrophotometer measurements. The spectral reflectance data for each sample from 380 to $700 \mathrm{~nm}$ were converted into colorimetric data using the DCI Color software. Reflectance measurements were recorded for each hair sample using an average of 4 measurements.

In 1976, CIE introduced the CIE-Lab three-dimensional color space. An important reason for the introduction was to standardize formulas for measuring color differences. Color distances should correspond as closely as possible to the perceived differences. Thus, the system is intended to create visual uniformity in the evaluation of color differences [12].

Hair color is expressed in terms of the $\mathrm{L}^{*}, \mathrm{a}^{*}, \mathrm{~b}^{*}$ color coordinates, where $\mathrm{L}^{*}$ corresponds to the lightness $(0=$ black, $100=$ white $), \mathrm{a}^{*}$ to the red-green coordinate $(-$ delta $\mathrm{e}$ green, +delta e red), and $\mathrm{b}^{*}$ to the yellow-blue coordinate $(-$ delta $\mathrm{e}=$ blue, + delta $\mathrm{e}=$ yellow) of a sample identifies a point in the 3D CIELAB color space that describes the color of the hair sample [13]. The color changes after each wash cycle were measured as $\Delta \mathrm{E}$. Absolute color differences are measured with the following, Euclidean color distance formula calculated as described in DIN 6174 as in formula (1) [14]:

$$
\Delta \mathrm{E}=\sqrt{\Delta \mathrm{L}^{2}+\Delta \mathrm{a}^{2}+\Delta \mathrm{b}^{2}} .
$$

\subsection{Statistical Analysis}

All data analyses were conducted using the software Statistica 13.0 (StatSoft Inc., Tulsa, OK, USA). One-way ANOVA and post-hoc Tukey test were conducted if the dataset was normal distributed and homogeneity of variance was given. If one of the abovementioned assumptions is not fulfilled the nonparametric Kruskal-Wallis test and afterwards the Dwass-Steel-Critchlow-Fligner test is conducted. All results are presented as box-whisker plots. The box defined by the mean \pm standard error (SE) and the whiskers represent the mean $\pm 1.96^{*}$ standard error, which give the limits of the confidence interval on $95 \%$ confidence level. 


\section{Patents}

Patent resulting from this manuscript with the following Number: DE102020214790.6.

Author Contributions: Conceptualization: L.S., T.H., H.M., V.V. Methodology: L.S., T.H., V.V., H.M. Formal analysis: L.S., H.M., T.H. Investigation: L.S. Data curation: L.S. Software: L.S., H.M. Writingoriginal draft preparation: L.S. Writing-review and editing: L.S. Visualization: L.S. Supervision: V.V., T.H., H.M. All authors have read and agreed to the published version of the manuscript.

Funding: This research was funded by Henkel AG\&Co KGaA.

Institutional Review Board Statement: Not applicable.

Informed Consent Statement: Not applicable.

Data Availability Statement: The data presented in this study are available on request from the corresponding author.

Acknowledgments: We are grateful to all R\&D members of the hair color level 3 department (Henkel AG\&Co KGaA, Germany) and the perfect cooperation with the University of Hamburg.

Conflicts of Interest: The authors declare no conflict of interest.

Sample Availability: Samples of the compounds are available from the authors.

\section{References}

1. Boga, C.; Delpivo, C.; Ballarin, B.; Morigi, M.; Galli, S.; Micheletti, G.; Tozzi, S. Investigation on the dyeing power of some organic natural compounds for a green approach to hair dyeing. Dyes Pigm. 2013, 97, 9-18. [CrossRef]

2. Tang, Y.; He, W.; Yang, S.; Liu, L. Stabilisation and detoxification of henna (Lawsonia inermis L.) extract for hair dye cosmetics by spray-drying encapsulation. Color. Technol. 2019, 135, 439-450. [CrossRef]

3. Dias, M.F.R.G. Hair Cosmetics: An Overview. Int. J. Trichology 2015, 7, 2-15. [CrossRef] [PubMed]

4. Wilson, H.; Carr, C.; Hacke, M. Production and validation of model iron-tannate dyed textiles for use as historic textile substitutes in stabilization treatment studies. Chem. Cent. J. 2012, 6, 1-13. [CrossRef] [PubMed]

5. Bechthold, T. Natural Colorants in Hair Dyeing. In Handbook of Natural Colorants; Bechthold, T., Mussak, R., Eds.; John Wiley \& Sons Ltd.: Chichster, UK, 2009; pp. 339-350.

6. Sargsyan, L.; Vill, V.; Hippe, T. Investigations of vegetable Tannins as Hair Dyes and their Interactions with pre-bleached hair fibres. Int. J. Cosmet. Sci. 2020, 42, 320-327. [CrossRef] [PubMed]

7. Pande, C.M.; Yang, B. Near-infrared spectroscopy: Applications in hair research. Int. J. Cosmet. Sci. 2000, 51, 183-192.

8. Miyamae, Y.; Yamakawa, Y.; Ozaki, Y. Evaluation of Physical Properties of Human Hair by Diffuse Reflactance Near-Infrared Spectroscopy. Appl. Spectrosc. 2007, 61, 212-217. [CrossRef] [PubMed]

9. Takafumi, I.; Kouji, T.; Norio, S.; Yoshinori, K.; Kunio, S.; Atsushi, I. Application of XANES profiles to X-ray spectromicroscopy for biomedical specimens: Part II. Mapping oxidation state of cysteine in human hair. J. X-Ray Sci. Technol 2011, 19, 313-320.

10. Covington, A.D. Modern tanning chemistry. Chem. Soc. Rev. 1997, 26, 111-126. [CrossRef]

11. The Tea Company GmbH \& Co. KG. Product Information File; The Tea Company GmbH \& Co. KG.: Neu Wulmstorf, Germany, 2019; p. 1.

12. Marchesi, J.J. Handbuch der Fotografie; Verlag Photographie: Gilching, Germany, 1998; p. 55.

13. Marsh, M.J. Hair Coloring. In Practical Modern Hair Science; Evans, T., Wickett, R., Eds.; Allured Business Media: Carroll Stream, IL, USA, 2012; p. 120.

14. Kidawa, N.; Simon, C. Perception of Noise Depending on Spatial Frequency and Contrast with the Aid of the CIE-Lab Color Space. Diploma Thesis, Imaging Science and Media Technology University of Applied Sciences, Cologne, Germany, 2003. 